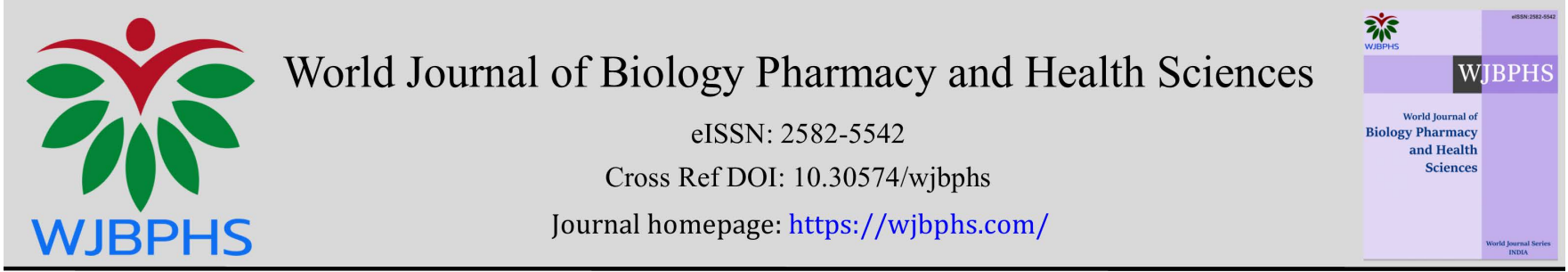

(RESEARCH ARTiCLE)

Check for updates

\title{
Antibacterial activities of leaves and seeds extracts of Datura stramonium on Salmonella Typhi and Shigella Species: Potential antimicrobial alternative for gastroenteritis
}

\author{
Edobor Peter Kenneth Imarenezor *, Onolunosen Abel Abhadionmhen, Samuel Tamunoiyowuna Cockeye \\ Brown, Joyce Briska, Paula Paul Shinggu and Sunday Danya
}

Tropical Diseases Unit, Department of Microbiology, Federal University Wukari, Taraba State, Nigeria.

World Journal of Biology Pharmacy and Health Sciences, 2022, 09(01), 005-012

Publication history: Received on 08 December 2021; revised on 10 January 2022; accepted on 12 January 2022

Article DOI: https://doi.org/10.30574/wjbphs.2022.9.1.0022

\begin{abstract}
Datura stramonium is a bushy annual plant belonging to the family Solanaceae. This study investigated the antimicrobial effects of methanolic and aqueous extracts of seeds and leave of Datura stramonium plant. The test organisms Salmonella Typhi and Shigella species were obtained from stock cultures at the National Veterinary Research Institute in Vom, Plateau State, Nigeria. The identification of the test organisms and the plant extracts were done using standard microbiological procedures. The results obtained showed that antibacterial activities of Methanolic leaf extracts of Datura stramonium produced inhibitions zone of $25 \mathrm{~mm}$ on concentration of $50 \mathrm{mg} / \mathrm{ml}$ and $25 \mathrm{~mm}$ on concentration of $100 \mathrm{mg} / \mathrm{ml}$ against Salmonella typhi while inhibition zone of $20 \mathrm{~mm}$, were observed on concentrations $25 \mathrm{mg} / \mathrm{ml}$, $50 \mathrm{mg} . \mathrm{ml}$ and $100 \mathrm{mg} / \mathrm{ml}$ against Shigella species. The aqueous leaves extracts produced no zone of inhibition against Salmonella typhi while zone of inhibitions of $10 \mathrm{~mm}$ was observed on concentration $50 \mathrm{mg} / \mathrm{ml}$ and $100 \mathrm{mg} / \mathrm{ml} \mathrm{against}$ Shigella species. The methanolic seeds extract produced zone of inhibition of $20 \mathrm{~mm}$ on both concentrations of $50 \mathrm{mg} / \mathrm{ml}$ and $100 \mathrm{mg} / \mathrm{ml}$ against Salmonella typhi while inhibition zones of $25 \mathrm{~mm}$ was observed on concentrations $50 \mathrm{mg} / \mathrm{ml}$ and $100 \mathrm{mg} / \mathrm{ml}$ against Shigella specie. The aqueous seeds extracts produced no zone of inhibition against both test organisms (Salmonella typhi and Shiegella species). The Minimum Inhibitory Concentration (MIC) of Datura stramonium methanolic leaves extract of Salmonella typhi was $12.5 \mathrm{mg} / \mathrm{ml}$ while Shigella Species had MIC of $25 \mathrm{mg} / \mathrm{ml}$. There was no MIC of aqueous leaves extract against Salmonella typhi while that of shigella species was $100 \mathrm{mg} / \mathrm{ml}$. The MIC of methanolic Seeds extract shows $25 \mathrm{mg} / \mathrm{ml}$ on both test organisms and no MIC of aqueous seed extract on both test organisms. This research has enormously revealed that extracts of Datura stramonium leaf possess more antimicrobial potency against Salmonella typhi and Shiegella species than the seed extracts. Also, the results also revealed that methanolic extract has more potency than the aqueous extract on either the leaves or seeds of Datura stramonium. Conclusively, Datura stramonium extracts demonstrated bactericidal potential against both Salmonella typhi and Shiegella species which indicate that the plant can be a good resource for herbal drugs that can be used against Gram negative bacteria.
\end{abstract}

Keywords: Antimicrobial; Aqueous; Datura stramonium; Leaf; Methanolic; Seed

\section{Introduction}

Antibiotic resistance continues to cause serious threat to global health [1]. Bacterial with resistant genes cause lifethreatening illness in humans and pose a significant threat to health and well-being [2]. The emergence of pathogens with resistance to clinically important antibiotics has stimulated the necessity of new treatment strategies thereby predisposing individuals to other serious opportunistic illnesses [3]. It is estimated that antibiotic-resistant pathogens

\footnotetext{
${ }^{*}$ Corresponding author: Edobor Peter Kenneth Imarenezor

Tropical Diseases Unit, Department of Microbiology, Federal University Wukari, Taraba State, Nigeria.

Copyright (C) 2022 Author(s) retain the copyright of this article. This article is published under the terms of the Creative Commons Attribution Liscense 4.0.
} 
are responsible for over 2 million illnesses and about 23,000 deaths annually in the U.S [4]. This has prompted the enormous exploration and adoption of mass production of plant-derived drugs by many pharmaceutical companies as a safe alternative to synthetic drugs which may not only be expensive but presents with various side effects [5]. Globally, various species of plants have been identified with significant bacteriostatic and bactericidal effects of many microorganisms. The WHO has recognized and permitted the use of more than 20,000 for medical purposes either as supplementary of alternative to chemotherapy [6] India has been able to mainstream the use of largely produced medicines from over 2000 plants species in treating ailments of various kinds [7]. Plants have been ascertained to possess the potency of exerting antibiotic action against drug-resistant microorganisms [8]. The phytochemical properties of plants together with their complex molecular features aid the disruption of antimicrobial resistance by bacterial [9].

Datura stramonium a member of the Solanaceae family is a bushy annual plant, alternatively known as Thorn Apple, Prickly Burr, Jimson Weed, Moon Flower, Devil's Weed, Devil's Cucumber and Devil's Trumpet [10]. Datura stramonium is native plant in North America, but grows wild in all temperate and moderate regions of the world [11]. The dull dark green upper surface of D. stramonium is up to $8 \mathrm{~cm}$ long and $6 \mathrm{~cm}$ across. The leaves are large and angular, uneven at the base. The stem is green or purple and largely hairless when old [12].D. stramonium plants may be toxic and fatal when not used properly owing to its dangerous levels of the tropane alkaloids atropine, hyoscyamine, and scopolamine, which are classified as deliriants. Datura stramonium has been ascertained to possess phytochemical properties including Tannins, Saponins, Alkaloids, Glycoside, Flavonoids, Steroids and Phenols [13]. The bioactive components many plants extracts are of high anti-microbial and anti-fungal activities [14]. Datura stramonium has been documented to be effective as spasmolytic, anti-asthmatic, anticholinergic, cerebral depressant, and nerve sedatives [15]. Nonetheless, bizarre behavior, hallucinations and amnesia are side effects presented from extensive use of the Devil weed [16]. This occurrence has highlighted the need for further research not only to understand its toxicological effects but, also extend to investigating the antimicrobial effects of its extracts on rapidly occurring pathogenic microorganisms [16]. In this research the antimicrobial potential of Datura stramonium extracts on gastroenteric pathogens Shigella and Salmonella typhi is revealed.

\section{Material and methods}

\subsection{Sample Collection}

Fresh samples of Datura Stramonium leaves stem and fruit were collected from Takum junction, Wukari, Taraba state. All the collected plant parts were identified by the Department of Crop Production and Protection, Federal University Wukari, and transported to the Microbiological laboratory, Federal University Wukari for further processing.

\subsection{Preparation of Extract}

The fresh Datura Stramonium leaf and seed were washed thoroughly with water to remove the adhering salts and other associated molecules, then cut into pieces the later pulverized using the mortar and pestle. The leaf was weighed $189 \mathrm{~g}$ and seed was also weighed $150 \mathrm{~g}$ was soaked in $300 \mathrm{ml}$ of $80 \%$ methanol and $300 \mathrm{ml}$ of sterile distilled water for 72 hours and then the soaked samples were filtered out using Whatman No.1 filter paper, then the filtrate was evaporated in Rotary Evaporater at $40^{\circ} \mathrm{C}$ and later heated at $100^{\circ} \mathrm{C}$ for two hours

\subsection{Isolation of Test Organisms}

The organisms Shigella spieces and Salmonella typhi were obtained from the National Veterinary Research Institute, Vom, Plateau State, Nigeria. After which each organism were sub-cultured on nutrient agar.

\subsection{Preparation of Media}

Mueller Hinton agar was used, and was prepared according to the manufacturer's specifications. The agar was prepared by dissolving $7 \mathrm{~g}$ each of the agar in $250 \mathrm{~m}$ of distilled water in separate conical flask. The media were than autoclaved at $121^{\circ} \mathrm{C}$ for 15 minutes. The sterilized media were allowed to cool to a temperature of $45^{\circ} \mathrm{C}$ and then approximately 20 $\mathrm{ml}$ was poured into sterile petri dish and allowed to gel.

\subsection{Antibacterial Activity}

The sensitivity testing of the Datura Stramonium plant extract was determined using agar-well diffusion method as described by [7]. The standard organisms were subcultured into peptone liquid broth and incubated for 18-24 hours. The turbidity of pure fresh cultures was adjusted with 0.5 McFarland turbidity standards. The isolates were later subcultured on to Mueller-Hinton agar. Wells were then bored into the agar medium using a sterile $6 \mathrm{~mm}$ cork borer. 
On each agar plate, about $0.2 \mathrm{mls}$ of the Datura Stramonium extracts was added to all the wells, the wells were then filled up with the solution of the extract and care was taken not to allow the solution to spill to the surface of the medium. The plates were incubated at $37^{\circ} \mathrm{C}$ for 24 hours. Ampicillin was used as a positive control. The plates were allowed to stand on the laboratory bench for between 1-2 hours to allow proper inflow of the solution into the medium before incubating the plates in an incubator at $37^{\circ} \mathrm{C}$ for 24 hours. The plates were later observed for the zones of inhibition by measuring the diameters of the zone of inhibition to the nearest milliliter.

\subsection{Determination of the Minimum Inhibitory Concentration (MIC)}

The MIC of the extracts was determined using method of [17]. Two-fold dilutions of the plant extracts were prepared and $2 \mathrm{ml}$ of different concentration of the solution was added to $18 \mathrm{ml}$ of pre-sterilized molten nutrient agar at temperature of $40^{\circ} \mathrm{C}$ to give final concentrations $100,50,25.12 .5$ and $6.25 \mathrm{mg} / \mathrm{ml}$. The medium was then poured into sterile Petri dishes and allowed to set. The surface of the medium was allowed to dry before streaking with 18 hours old isolates. Ampicillin was used as a positive control. The plates were later incubated in an incubator at $37^{\circ} \mathrm{C}$ for up to 24 hours after which they were examined for the presence or absence of growth. The MIC was taken as the lowest concentration that will prevent the bacterial growth.

\section{Results}

Tables 1 - 4 below show the result of the antimicrobial effects of different concentrations of methanol and aqueous extracts of Datura stramonium leaves and seeds on Salmonella typhi and Shigella. The minimum inhibitory concentration of Datura stramonium methanol leaves and seeds extracts against the test organisms Salmonella typhi and Shigella are presented in Tables 5-8.

Table 1 Antibacterial activity of Methanol leaves extract of Datura stramonium showing the zone of inhibition (mm)

\begin{tabular}{|c|c|c|c|c|c|c|}
\hline & \multicolumn{6}{|c|}{ CONCENTRATIONS (mg/ml) } \\
\hline ORGANISMS & $\mathbf{6 . 2 5}$ & $\mathbf{1 2 . 5}$ & $\mathbf{2 5}$ & $\mathbf{5 0}$ & $\mathbf{1 0 0}$ & Positive control \\
\hline Salmonella typhi & - & - & - & $25 \mathrm{~mm}$ & $25 \mathrm{~mm}$ & $25 \mathrm{~mm}$ \\
\hline Shigella species & - & - & $20 \mathrm{~mm}$ & $20 \mathrm{~mm}$ & $20 \mathrm{~mm}$ & $20 \mathrm{~mm}$ \\
\hline
\end{tabular}

Table 2 Antibacterial activity of Aqueous leaves extract of Datura stramonium showing the zone of inhibition (mm)

\begin{tabular}{|l|c|c|c|c|c|c|}
\hline & \multicolumn{6}{|c|}{ CONCENTRATIONS (mg/ml) } \\
\hline ORGANISMS & $\mathbf{6 . 2 5}$ & $\mathbf{1 2 . 5}$ & $\mathbf{2 5}$ & $\mathbf{5 0}$ & $\mathbf{1 0 0}$ & Positive control \\
\hline Salmonella typhi & & - & - & - & - & $20 \mathrm{~mm}$ \\
\hline Shigella species & & - & - & $10 \mathrm{~mm}$ & $10 \mathrm{~mm}$ & $15 \mathrm{~mm}$ \\
\hline
\end{tabular}

KEY; (-): No Inhibition

Table 3 Antibacterial activity of Methanol seeds extract of Datura stramonium showing the zone of inhibition (mm)

\begin{tabular}{|l|c|c|c|c|c|c|}
\hline & \multicolumn{6}{|c|}{ CONCENTRATIONS (mg/ml) } \\
\hline ORGANISMS & $\mathbf{6 . 2 5}$ & $\mathbf{1 2 . 5}$ & $\mathbf{2 5}$ & $\mathbf{5 0}$ & $\mathbf{1 0 0}$ & Positive control \\
\hline Salmonella typhi & & - & - & $20 \mathrm{~mm}$ & $20 \mathrm{~mm}$ & $20 \mathrm{~mm}$ \\
\hline Shigella species & & - & - & $25 \mathrm{~mm}$ & $25 \mathrm{~mm}$ & $20 \mathrm{~mm}$ \\
\hline
\end{tabular}


Table 4 Antibacterial activity of aqueous seeds extract of Datura stramonium showing the zone of inhibition (mm)

\begin{tabular}{|l|c|c|c|c|c|c|}
\hline & \multicolumn{6}{|c|}{ CONCENTRATIONS (mg/ml) } \\
\hline ORGANISMS & $\mathbf{6 . 2 5}$ & $\mathbf{1 2 . 5}$ & $\mathbf{2 5}$ & $\mathbf{5 0}$ & $\mathbf{1 0 0}$ & Positive control \\
\hline Salmonella typhi & & - & - & - & - & $20 \mathrm{~mm}$ \\
\hline Shigella species & & - & - & - & - & $20 \mathrm{~mm}$ \\
\hline
\end{tabular}

KEY; (-): No Inhibition

Table 5 MIC of aqueous seeds extract of Datura stramonium showing the zone of inhibition (mm)

\begin{tabular}{|l|c|c|c|c|c|}
\hline & \multicolumn{5}{|c|}{ CONCENTRATIONS (mg/ml) } \\
\hline ORGANISMS & $\mathbf{6 . 2 5}$ & $\mathbf{1 2 . 5}$ & $\mathbf{2 5}$ & $\mathbf{5 0}$ & $\mathbf{1 0 0}$ \\
\hline Salmonella typhi & - & + & - & - & - \\
\hline Shigella species & + & - & + & - & - \\
\hline
\end{tabular}

KEY; (-): No Inhibition; (+): Inhibition

Table 6 MIC of Aqueous Leaves extract of Datura stramonium showing the zone of inhibition (mm)

\begin{tabular}{|l|c|c|c|c|c|}
\hline & \multicolumn{5}{|c|}{ CONCENTRATIONS (mg/ml) } \\
\hline ORGANISMS & $\mathbf{6 . 2 5}$ & $\mathbf{1 2 . 5}$ & $\mathbf{2 5}$ & $\mathbf{5 0}$ & $\mathbf{1 0 0}$ \\
\hline Salmonella typhi & - & - & - & - & - \\
\hline Shigella species & - & - & - & - & - \\
\hline
\end{tabular}

KEY(-): No Inhibition; (+): Inhibition

Table 7 MIC of methanolic Seeds extract of Datura stramonium showing the zone of inhibition (mm)

\begin{tabular}{|l|c|c|c|c|c|}
\hline & \multicolumn{6}{|c|}{ CONCENTRATIONS (mg/ml) } \\
\hline ORGANISMS & $\mathbf{6 . 2 5}$ & $\mathbf{1 2 . 5}$ & $\mathbf{2 5}$ & $\mathbf{5 0}$ & $\mathbf{1 0 0}$ \\
\hline Salmonella typhi & - & - & + & - & - \\
\hline Shigella species & - & - & + & - & - \\
\hline \multicolumn{7}{|c|}{ KEY (-): No Inhibition; (+): Inhibition }
\end{tabular}

Table 8 MIC of Aqueous seeds extract of Datura stramonium showing the zone of inhibition (mm)

\begin{tabular}{|l|c|c|c|c|c|}
\hline & \multicolumn{5}{|c|}{ CONCENTRATIONS (mg/ml) } \\
\hline ORGANISMS & $\mathbf{6 . 2 5}$ & $\mathbf{1 2 . 5}$ & $\mathbf{2 5}$ & $\mathbf{5 0}$ & $\mathbf{1 0 0}$ \\
\hline Salmonella typhi & - & - & - & - & - \\
\hline Shigella species & - & - & - & - & - \\
\hline
\end{tabular}

KEY- (-): No Inhibition; (+): Inhibition 


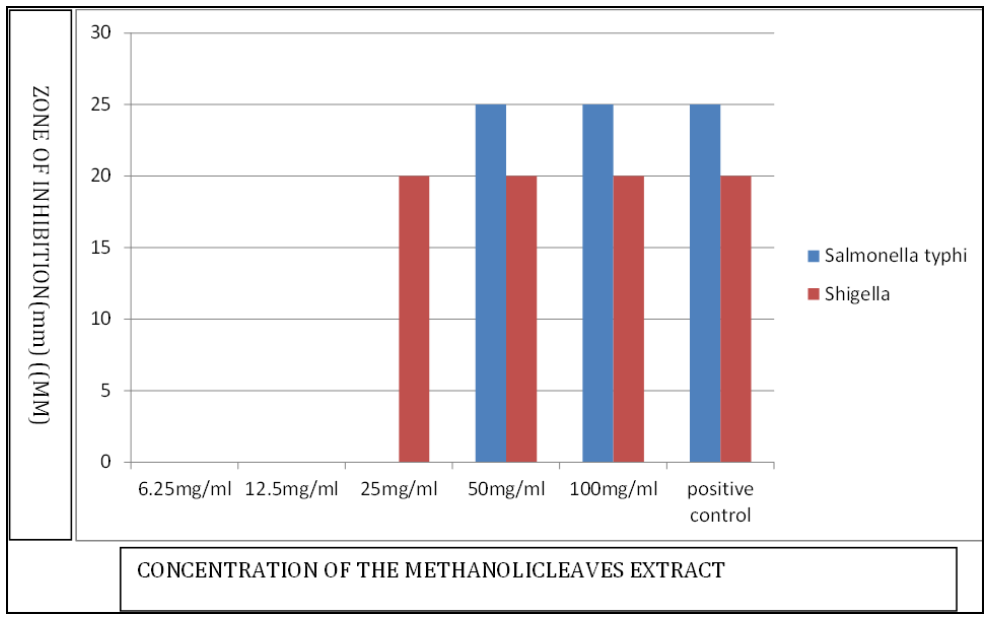

Figure 1 Antibacterial activity of Methanolic Datura stramonium leaves extracts on Salmonella typhi and Shigella

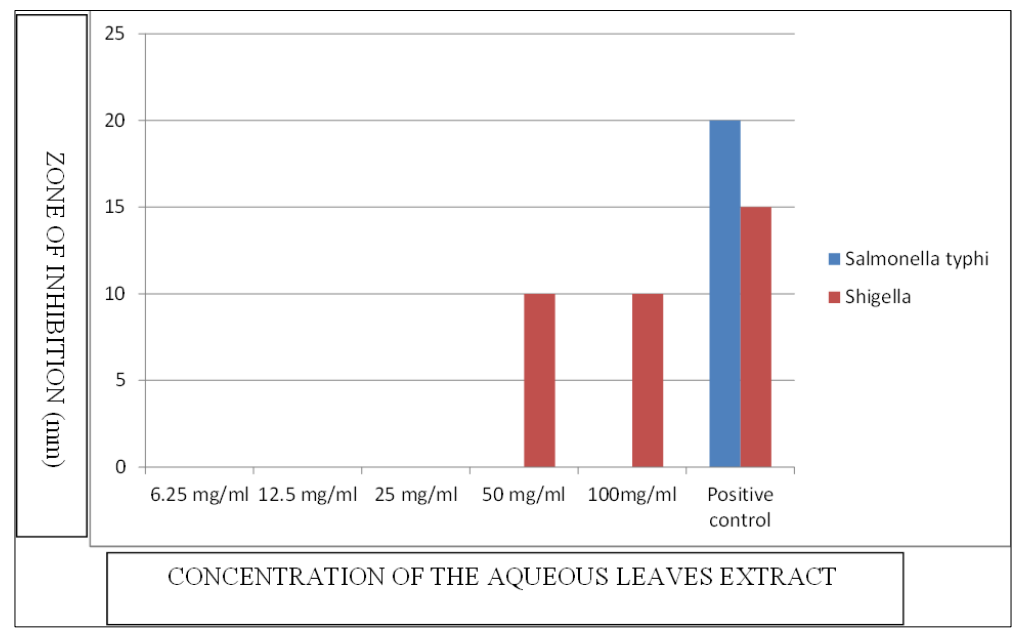

Figure 2 Antibacterial activity of Aqueous Datura stramonium leaves extracts on Salmonella typhi and Shigella

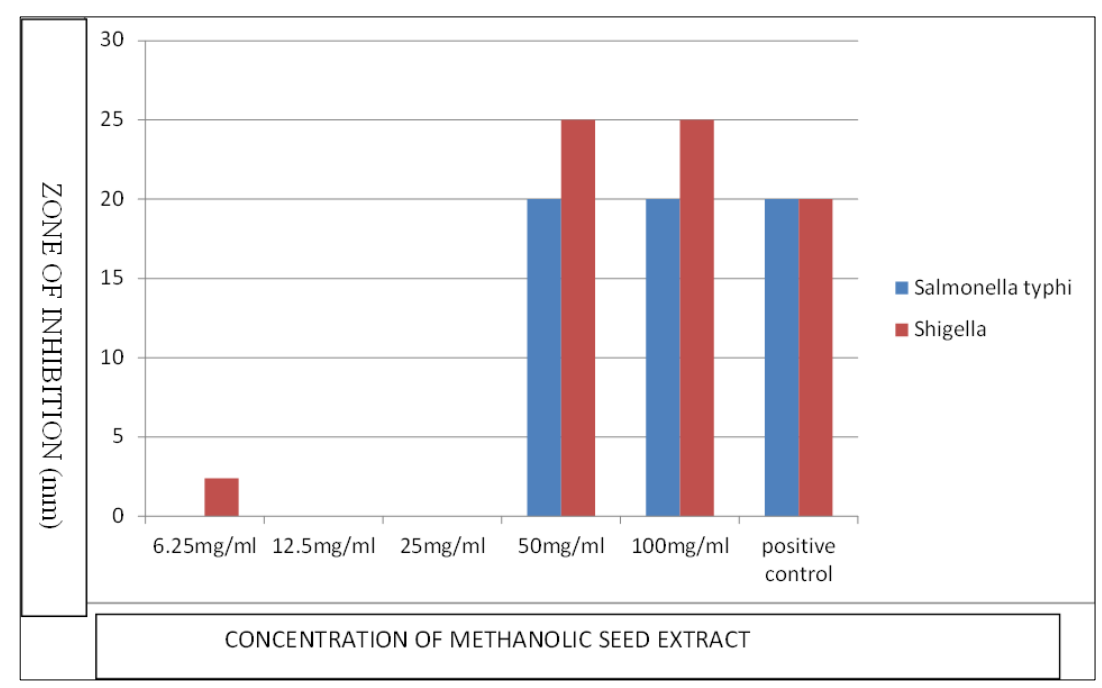

Figure 3 Antibacterial activity of Methanolic Datura stramonium seeds extracts on Salmonella typhi and Shigella 


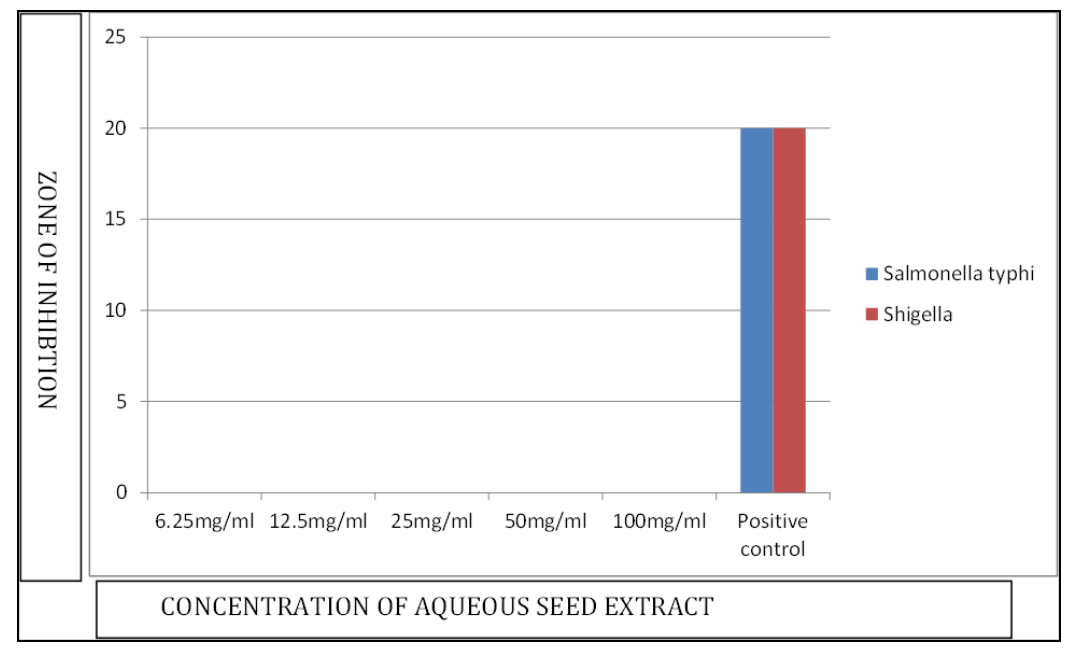

Figure 4 Antibacterial activity of Aqueous Datura stramonium seeds extracts on Salmonella typhi and Shigella

\section{Discussion}

The results from this research have presented distinctiveness in the antibacterial effects at various concentrations of aqueous and methanolic extracts of Datura stramonium on the test organisms, Salmonella typhi and Shigella specie. Methanolic extracts of Datura stramonium seeds and leaves indicated significant antimicrobial effects at $25 \mathrm{mg} / \mathrm{ml}, 50$ $\mathrm{mg} / \mathrm{ml}$ and $100 \mathrm{mg} / \mathrm{ml}$ concentrations as inhibitory effect ranging from 20mm and 25mm was observed for Salmonella typhi and Shigella specie. Contrastingly the aqueous extracts of both seeds and leaves of Datura stramonium presented insignificant inhibitory activity on Salmonella typhi and Shigella specie except that, at $50 \mathrm{mg} / \mathrm{ml}$ and $100 \mathrm{mg} / \mathrm{ml}$ concentrations of aqueous extracts of Datura stramonium leaves $10 \mathrm{~mm}$ of inhibitory activity was observed for Shigella specie only. Consequently, methanolic extracts of Datura stramonium seeds and leaves has more antimicrobial effects than the aqueous extracts on Salmonella typhi and Shigella specie when compared with the positive control (Ampicillin). Relating to this current finding, [11] had observed that the therapeutic efficacy of Datura stramonium extracts transcends spasmolytic, anti-asthmatic, anticholinergic and antimalarial but extends to antibacterial effects as a panel of bacterial has been observed to be susceptible to methanolic extracts of the plant. Methanol extracts has been recommended by many studies to be more potent in extracting antimicrobials from plants. According to [6] methanolic and acetone are more effective solvents than the aqueous solution in their study to investigate the antibacterial activities of extracts of leaf, fruit, seed and bark of Phoenix dactylifera. This study has confirmed previous findings on the potency of methanol when compared with water in extracting phytochemicals of antimicrobial relevance from plant [18] This current study has made explicit that, seed extracts of Datura stramonium showed less antimicrobial efficacy than leave extracts on the test organisms. Many studies have argued the medicinal and antimicrobial supremacy of leave and seed extracts over each other. [19] discovered over 50\% antimicrobial efficacy of the leave extracts of Bixa orellana L. compared to its seed extracts. Contrastingly, concluded that although Moringa peregrina extracts has an inhibitory effect on ileum contractions but the seed extract was more potent than the leave extracts [20]. The distinction here is mainly that various parts of plants are constituted with different phytochemicals, having different antimicrobial effects on different microorganisms.

\section{Conclusion}

This research emphasizes the increasing abilities which plants have continued to show in antimicrobial advancement. Eventually, the extracts of Datura stramonium has been observed to inhibit the growth of Shigella and Salmonella typhi and consequently suggested as a good natural antimicrobial candidate for advancing the therapeutic efforts of treating clinical cases of multi-drug resistant gastroenteric pathogens.

\section{Compliance with ethical standards}

\section{Acknowledgments}

We acknowledged the contributions of the Laboratory staff of Department of Microbiology, Federal University Wukari and the National Veterinary Research Institute in Vom, Plateau State, Nigeria for creating a friendly environment for the analysis of samples. 


\section{Disclosure of conflict of interest}

The authors (Edobor Peter Kenneth Imarenezor, Onolunosen Abel Abhadionmhen, Samuel Tamunoiyowuna Cockeye Brown, Joyce Briska, Paula Paul Shinggu and Sunday Danya) declare no conflict of interest.

\section{Statement of informed consent}

All participants were adequately prepared for the study; were given health education, all necessary information provided and voluntarily signed consent form.

\section{References}

[1] New report calls for urgent action to avert antimicrobial resistance crisis: World Health Organization (WHO). 2019.

[2] Divek VTN, Venkitanarayanan K, Kollanoor A. Antibiotic-resistant Salmonella in the food supply and the potential role of antibiotic alternatives for control. Foods. 2018; 7: 167-291.

[3] Abalaka ME, Daniyan SY, Oyeleke SB, Adeyemo SO. The antibacterial evaluation of moringa oleifera leaf extract on selected bacterial pathogens. Research Journal of Microbiology. 2012; 2(2): 1-4.

[4] Bell BG, Schellevis F, Stobberingh E, Goossens H, Pringle M. A systematic review and meta-analysis of the effects of antibiotic consumption on antibiotic resistance. BMC Infect. Dis. 2014; 14: 1471-2334.

[5] Centers for Disease Control and Prevention (CDC). Antibiotic Resistance Threats in the United States cdc. 2013.

[6] Sooad Al-daihan, Ramesa Shafi Bhat. Antibacterial activities of extracts of leaf, fruit, seed and bark of Phoenix dactylifer. African Journal of Biotechnology. 2012; 11(42): 10021-10025.

[7] Imarenezor EPK, Abhadionmhen OA, Briska J, Shinggu PP, Danya S. Antimicrobial properties of Vernonia amygdalina on Escherichia coli and Proteus species isolated from urine samples: Potential antimicrobial alternative for urinary tract infection. International Journal of Biological and Pharmaceutical Sciences Archive. 2021; 02(01): 127-134.

[8] Eleyinmi AF, Sporns P, Bressler DC. Nutritional composition of Gongronema latifolium and Vernonia amygdalina. Nutrition of Food Science. 2008; 38: 99-109.

[9] Wall MG, Wani MC, Manikuma G, Abraham P, Taylor H, Hughes TJ, Warner J, Macgivney R. Plants antimutagenic agent, flavonoids. Journal of natural production. 2002; 51: 1084-1089.

[10] Vlietinck AJ, Hoof LV, Totte J, Lasure A, Berghe DV. Screening of hundred Rwandese medicinal plants for antimicrobial and antiviral properties. Journal of Ethnopharmacology. 2000; 46: 31-47.

[11] Gachande B, Khillare E. In-vitro evaluation of Datura species for potential. Antimicrobial activity. Bioscience Discovery. 2013; 4(1): 78-81.

[12] Veblen KE. Savanna glade hotspots: Plant community development and synergy with large herbivores. Journal of Arid Environments. 2012; 78: 119-127.

[13] EPK Imarenezor, FU Ebuara, OA Abhadionmhen, STC Brown, D Apine, K Isaac. Antibacterial activity of some selected medicated soap on staphylococcus aureus from wound infections GSJ. 2020; 8(9): 1196-1205.

[14] EPK Imarenezor, STC Brown, OE Yakubu, PA Egwaikhide, SP Malu, JT Ugye. Efficiency of chickweed (stellaria citrifolia) leaves extract on dermatophytes (ringworms) isolated from primary school pupils in Wukari, North East, Nigeria. FUW Trends in Science \& Technology Journal. 2018; 3(2): 615 - 618.

[15] EPK Imarenezor, FU Ebuara, OA Abhadionmhen, STC Brown, K Isaac. Antimicrobial effects of chromolaena odorata leaves on Staphylococcus aureus and Streptococcus spp isolates from urine of patients attending general hospital Wukari, North East, Nigeria. GSJ. 2020; 8(9): 1183-1195.

[16] Soni P, Siddiqui AA, Dwivedi J, Soni V. Phamarcological properties of Datura stramonium L. as a potential medicinal tree: An overview. Asian Pacific Journal of Tropical Biomedicine. 2012; 2(12): 1002 - 1008.

[17] Srivastava R, Srivastava P. The Medicinal Significance of Datura stramonium; A Review. Biomedical Journal of Scientific \& Technical Research. 2020; 29(2): 22223 - 22226.

[18] Akinpelu DA, Kolawole DO. Phytochemical and antimicrobial activity of leaf extract of Piliostigma thonningii (Shumm), Science Focus. 2004; 7: 64 - 70. 
[19] Tamil Selvi A, Dinesh MG, Satyan RS, Chandrasekaran B, Rose C. Leaf and Seed extracts of Bixa orellana L. exert anti-microbial activity against bacterial pathogens; Journal of Applied Pharmaceutical Science. 2011; 01(09): 116-120.

[20] Sadraei H, Asghari G, Farahnaki F. Assessment of hydroalcoholic extract of seeds and leaves of Moringa peregrina on ileum spasm. Research in Pharmaceutical Sciences. 2015; 10(3): 252-258. 